SHORT REPORT

\title{
Vascular endothelial growth factor (VEGF) is increased in serum, but not in cerebrospinal fluid in HIV associated CNS diseases
}

\author{
B Sporer, U Koedel, R Paul, J Eberle, G Arendt, H-W Pfister
}

J Neurol Neurosurg Psychiatry 2004;75:298-300. doi: 10.1136/jnnp.2003.016287

\begin{abstract}
Vascular endothelial growth factor (VEGF) is a potent angiogenic and mitogenic peptide, which also induces several mediators that may play a role in HIV induced CNS damage. VEGF levels were determined in cerebrospinal fluid (CSF) and serum samples from patients with $(n=8)$ and without $(n=19)$ directly HIV associated CNS disorders and HIV negative control patients ( $n=18)$. VEGF serum but not CSF levels were significantly increased in HIV infected patients with (381.1 (78.9) pg/ml) HIV associated CNS diseases compared with those without (120.8 (13.1) pg/ml) and HIV negative control patients (133.1(14.8) pg/ml). Serum samples from patients with untreated HIV associated encephalopathy (HIVE, $n=3$ ) contained the highest VEGF levels $(583.9(71.5) \mathrm{pg} / \mathrm{ml})$. In two patients VEGF serum levels were reduced during antiretroviral therapy. However, regardless of effective viral suppression, patients with HIVE still had higher levels compared with HIV infected patients without HIVE. A relevant increase of serum VEGF was not observed in patients without HIVE though high $\mathrm{HI}$ viral load. We conclude that HIVE is associated with increased serum VEGF levels. Further studies are warranted to elucidate the role of VEGF in HIVE.
\end{abstract}

$\mathrm{V}$ ascular endothelial growth factor (VEGF) is a potent angiogenic and mitogenic peptide. When activated by different stimuli, such as cytokines, oxidative stress, and hypoxia, it induces angiogenesis, ${ }^{1}$ extracellular matrix degradation $^{2}$ and tubular formation. ${ }^{3}$ In addition, VEGF acts as a potent regulator of vascular permeability ${ }^{4}$ and is known as "vascular permeability factor". Furthermore, VEGF has chemotactic effects on leucocytes ${ }^{1}$ and induces a variety of mediators that are crucial in inflammation and have also been suggested to be involved in HIV neuropathogenesis, such as matrix metalloproteinases ${ }^{56}$ and adhesion molecules. ${ }^{7}$ In the SCID (severe combined immunodeficiency disease) mouse model of HIV encephalopathy (HIVE), induction of brain VEGF protein was observed by immunohistochemistry ${ }^{8}$. Increased serum levels of VEGF have been reported in HIV infected patients with Kaposi sarcoma. ${ }^{90}$ Yet the potential role of VEGF in HIV associated central nervous system (CNS) injury has not been characterised.

To determine the involvement of VEGF in HIV associated CNS damage, the cerebrospinal fluid (CSF) and serum levels of this peptide were measured. Samples from HIV infected patients with or without CNS complications and a HIV negative control group were examined. The results were correlated with other laboratory parameters such as the blood CD4 cell count, the CSF white blood cell count, the CSF total protein content, the CSF to serum albumin ratio (a parameter for the integrity of the blood-brain barrier), and the CSF and plasma HI-viral load (table 1).

\section{INVESTIGATIONS AND RESULTS}

CSF and corresponding serum samples from 27 HIV infected and 18 control patients, admitted to the Department of Neurology at the University of Munich between 1996 and 2002, were collected and analysed. CSF was drawn for diagnostic purposes after the patient's informed consent was obtained. It was centrifuged within 20 minutes and the supernatant was stored at $-40{ }^{\circ} \mathrm{C}$. The patients infected with HIV were subdivided into two groups: Group 1 consisted of 19 HIV infected patients without CNS disorders, mainly patients with tension headache and distal symmetric polyneuropathy. Group 2 comprised eight HIV infected patients with HIV induced CNS complications, including six patients with chronic HIVE, one patient with HIV associated myelopathy, and one patient with acute HIV associated meningitis. The control group consisted of 18 HIV negative patients with non-inflammatory neurological disorders, mainly patients with tension headache or headaches induced by exercise. CSF investigations were done in all patients to exclude, for example, subarachnoidal haemorrhage or (opportunistic) CNS infections.

VEGF concentrations were determined by a commercially available chemiluminescent sandwich enzyme immunoassay (R\&D Systems, Minneapolis, United States) according to the manufacturer's guidelines. Statistical analysis of group differences was performed by non-parametric procedures (Kruskal Wallis one way analysis of variance and the Mann Whitney $U$ test including alpha correction). p values $<0.05$ were considered significant.

The CSF VEGF levels did not differ between all investigated groups (HIV group l: 42.6 (8.2) pg/ml; HIV group 2: 49.7 (15.2) pg/ml; control group: 43.7 (7.9) pg/ml). In contrast, serum VEGF levels were significantly increased $(\mathrm{p}<0.02$; Mann Whitney $U$ test $)$ in patients with HIV induced CNS complications compared with HIV infected patients without CNS disorders and HIV negative controls (HIV group 1: 120.8 (13.1) pg/ml; HIV group 2: 381.1 (78.9) $\mathrm{pg} / \mathrm{ml}$; controls: 133.1 (14.8) $\mathrm{pg} / \mathrm{ml}$ ) (see figure 1 ). The serum samples from patients with untreated HIVE $(\mathrm{n}=3)$ contained the highest VEGF levels (583.9 (71.5) pg/ $\mathrm{ml}$ ). "Follow up" samples were available for two of these patients. They showed that VEGF concentrations had decreased during antiretroviral therapy and clinical improvement (patient one: 670 to $304 \mathrm{pg} / \mathrm{ml}$; patient two: 441 to

Abbreviations: CSF, cerebrospinal fluid; HIVE, HIV associated encephalopathy; VEGF, vascular endothelial growth factor 
Table 1 CSF findings, blood CD4 cell count, and CSF and plasma HI-viral load in different groups of HIV infected patients and control patients

\begin{tabular}{|c|c|c|c|c|c|c|}
\hline Groups & $\begin{array}{l}\text { CSF white blood } \\
\text { cell count } \\
\text { cells } / \mu \mathrm{l}\end{array}$ & $\begin{array}{l}\text { CSF total protein } \\
\text { content } \\
\text { g/l }\end{array}$ & $\begin{array}{l}\text { CSF to serum } \\
\text { albumin ratio } \\
\times 1000\end{array}$ & $\begin{array}{l}\text { blood CD4 cell count } \\
\text { CD4/ } / \mathrm{l}\end{array}$ & $\begin{array}{l}\text { CSF HI-viral load } \\
\mathrm{c} / \mathrm{ml}\end{array}$ & $\begin{array}{l}\text { Plasma HI-viral load } \\
\mathrm{c} / \mathrm{ml}\end{array}$ \\
\hline $\begin{array}{l}\text { HIV group } 1(n=19) \\
\text { (no CNS disease) }\end{array}$ & $3.6(1.2)$ & $0.41(0.02)$ & $5.3(0.3)$ & $248.5(40.9)$ & $4830(2396)$ & 44834 (13102) \\
\hline $\begin{array}{l}\text { HIV group } 2(n=8) \\
\text { (HIV induced CNS } \\
\text { disease) }\end{array}$ & $26.6(4.3)^{*}$ & $0.54(0.10)^{*}$ & $7.9(1.1)^{*}$ & $228.6(65.8)$ & 22440 (12716) & $75128(60506)$ \\
\hline $\begin{array}{l}\text { Control patients } \\
(n=18)\end{array}$ & $1.7(0.3)$ & $0.28(0.02)$ & $3.7(0.3)$ & nd & nd & nd \\
\hline
\end{tabular}

Data are presented as mean (standard error); nd, not done

*The CSF WBC count, the total protein levels and the CSF to serum albumin ratio were significantly increased in patients with HIV induced CNS complications compared with HIV negative controls, but not compared with HIV infected patients without CNS complications ( $p<0.05$; Mann Whitney U test).

$210 \mathrm{pg} / \mathrm{ml})$. On the basis of a cut off value of $206 \mathrm{pg} / \mathrm{ml}$ ( = mean +2 standard deviations (HIV negative control patients)) all patients with HIVE but no patients without HIVE had increased VEGF serum levels. Statistical analysis revealed no significant correlation between VEGF serum concentrations and serum and CSF HI viral load as well the other CSF parameters.

\section{DISCUSSION}

Taken together, the current study shows for the first time that serum VEGF is increased in patients with HIVE and reduced by antiretroviral therapy. Additionally patients with HIVE and effective antiretroviral treatment had lower serum VEGF levels compared to those without effective therapy. However, regardless of effective viral suppression patients

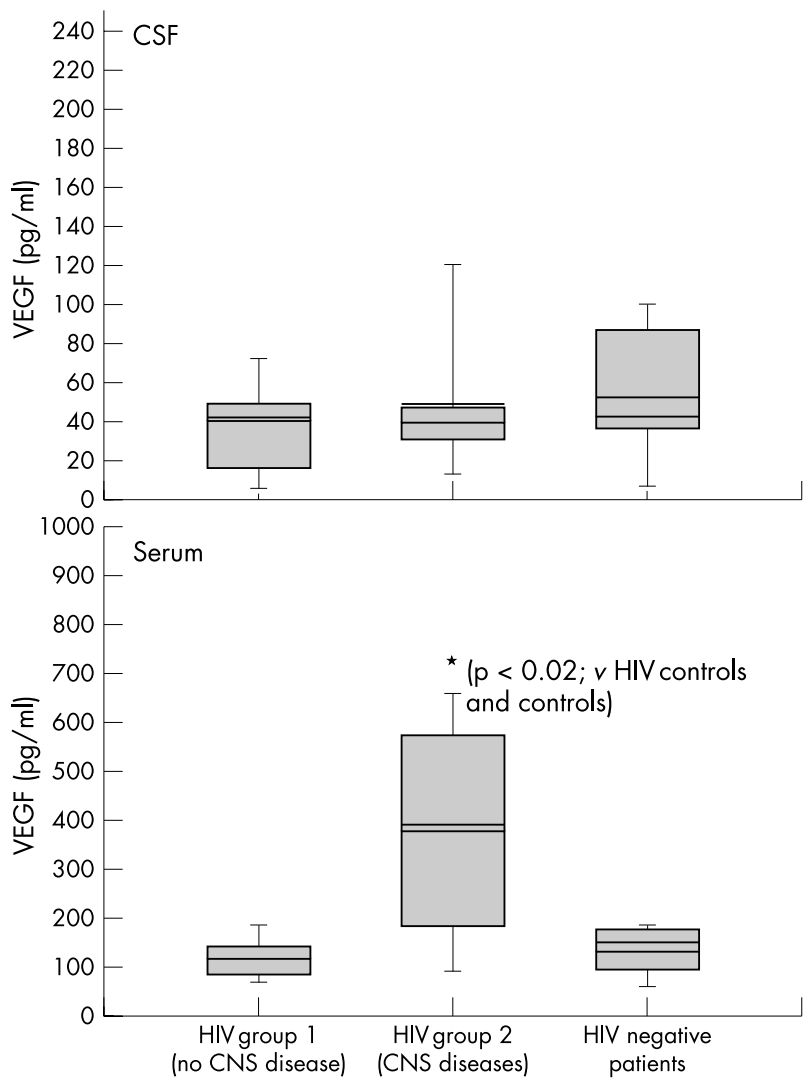

Figure 1 CSF and serum VEGF levels in HIV infected patients without or with CNS involvement and HIV negative control patients $(p<0.02$; Mann Whitney $\mathrm{U}$ test). with HIVE still had higher levels compared with those without HIVE. A relevant increase of serum VEGF was not observed in patients without HIVE though high HI viral load. Thus, HIVE seems to be associated with increased serum VEGF levels. Potential cellular sources of serum VEGF may be T lymphocytes and monocytes. Both cell types are main targets of HIV, but up to now only T lymphocytes have been observed to release VEGF after infection with HIV. ${ }^{10}$

In the current study CSF VEGF concentrations were not increased in HIV infected patients with or without CNS complications, arguing against a substantial upregulation within the CNS and a major relevance of brain derived VEGF in HIV neuropathogenesis. However, HIV induced CNS disorders are generally chronic, show only mild inflammation, and affect mainly deep brain structures. Thus, a subtle upregulation of brain VEGF may not be detected in the CSF.

It is known that VEGF can lead to endothelial cell activation and-for example-the upregulation of adhesion molecules and inflammatory mediators, which are thought to contribute to HIV induced CNS damage. ${ }^{7}$ VEGF may hypothetically force leucocytes to migrate into the CNS, a commonly accepted crucial step in HIV neuropathogenesis. ${ }^{11}$ Immigrated leucocytes may then serve as a viral reservoir as well as a source of inflammatory and neurotoxic substances and therefore be able to propagate CNS injury during HIV infection.

In addition, recent investigations highlight neuroprotective characteristics of VEGF. ${ }^{12}$ Thus, it is conceivable that the increased release of VEGF during HIVE may have beneficial features-for example, by its stimulating effects on growth and survival of neurones and glial cells. ${ }^{12}$

All in all, increased serum VEGF levels are strongly associated with HIV encephalopathy and partly reduced by specific HIV therapy. Further studies are warranted to characterise the functional role of VEGF in this serious neurological disorder.

\section{ACKNOWLEDGEMENTS}

We thank Dr M Wick, Institute for Clinical Chemistry, for clinical cooperation, Ms S Walter and B Angele for excellent technical assistance, and Ms J Benson for editing the manuscript.

\section{Authors' affiliations}

G Arendt, Department of Neurology, Heinrich Heine-University, Düsseldorf, Germany

B Sporer, U Koedel, R Paul, H-W Pfister, Department of Neurology, Ludwig-Maximilians University, Munich, Germany

J Eberle, Max von Pettenkofer Institute for Hygiene and Medical Microbiology, Ludwig-Maximilians University, Munich, Germany 
This work was supported by a grant from the Ludwig MaximiliansUniversity, Munich, to B Sporer (Förderprogramm für Forschung und Lehre).

This study was in part presented at the conjoint meeting of the $4^{\text {th }}$ International Symposium on NeuroVirology and the $10^{\text {th }}$ Conference on Neuroscience on HIV Infection, June 2002, Düsseldorf, Germany.

Competing interests: none declared

Correspondence to: B Sporer, Department of Neurology, LudwigMaximilians-University, Marchioninistr. 15, 81377 Munich, Germany; BSPORER@nefo.med.uni-muenchen.de

Received 4 April 2003

In revised form 2 July 2003

Accepted 9 July 2003

\section{REFERENCES}

1 Ferrara N. VEGF: an update on biological and therapeutic aspects. Curr Opin Biotechnol 2000;11:617-24.

2 Esser S, Wolburg K, Wolburg H, et al. Vascular endothelial growth factor induces endothelial fenestrations in vitro. J Cell Biol 1998;140:947-59.
3 Mühlhauser J, Merrill MJ, Pili R, et al. VEGF165 expressed by a replicationdeficient recombinant adenovirus vector induces angiogenesis in vivo. Circ Res 1995;77:1077-86.

4 Paul R, Zhang ZG, Eliceiri BP, et al. Src deficiency or blockade of Src activity in mice provides cerebral protection following stroke. Nat Med 2001 7:222-7.

5 Sporer B, Paul R, Koedel U, et al. Detection of matrixmetalloproteinase- 9 in the cerebrospinal fluid of HIV-infected patients. J Infect Dis 1998;178:854-7.

6 Sporer B, Koedel U, Paul R, et al. Human immunodeficiency virus type-1 Nef protein induces blood-brain barrier disruption in the rat: role of matrix metalloproteinase-9. J Neuroimmunol 2000;102:125-30.

7 Heidenreich F, Arendt G, Jander S, et al. Serum and cerebrospinal fluid levels of soluble intercellular adhesion molecule 1 (sICAM-1) in patients with HIV-1 associated neurological diseases. J Neuroimmunol 1994;52:117-26.

8 Persidsky Y, Limoges J, McComb R, et al. Human immunodeficiency virus encephalitis in SCID mice. Am J Pathol 1996;149:1027-53.

9 Mercie P, Devianne I, Viallard JF, et al. Vascular endothelial growth factor (VEGF165) plasma level increase with immunodepression in AIDS patients with Kaposi's sarcoma. Microvasc Res 1999:57:208-10.

10 Ascherl G, Hohenadl C, Schatz O, et al. Infection with human immunodeficiency virus-1 increases expression of vascular endothelial cell growth factor in T cells: implications for acquired immunodeficiency syndrome-associated vasculopathy. Blood 1999;93:4232-41.

11 Glass JD, Fedor H, Wesselingh SL, et al. Immuncytochemical quantitation of human immunodeficiency virus in the brain: correlation with dementia. Ann Neurol 1995; 38:755.

12 Carmeliet $\mathbf{P}$, Storkebaum E. Vascular and neuronal effects of VEGF in the nervous system: implications for neurological disorders. Semin Cell Dev Biol 2002;13:39-53.

\section{$\mathrm{ECHO}$}

\section{Mutations in the neurofibromatosis type 1 gene}

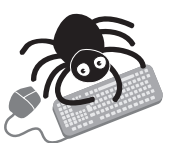

Please visit the Journal of

Neurology, Neurosurgery, and Psychiatry website [www.jnnp. com] for a link to the full text of this article. eurofibromatosis type 1 (NFl) affects about one person in 3500 and is one of the $\mathrm{N}$ most common human autosomal dominant disorders. The gene is very large $(60$ exons spanning more than $300 \mathrm{~kb}$ of genomic DNA) and the mutation rate is high. Linkage analysis, used in many centres, is unhelpful for the $50 \%$ of cases arising from new mutations. Analysis of NFI mRNA has demonstrated a variety of new and recurrent (previously recognised) mutations. Researchers in Spain studied 474 unrelated people with suspected NFl.

A firm clinical diagnosis was made in 201 of the 474 (42\%). Mutational screening of the whole NFl coding region was carried out using the cDNA-SSCP/HD approach and a total of 142 different NFl mutations were identified in 189 patients. Of these 142 mutations 104 were previously undescribed and the remaining 38 were either already known or detected more than once in this study. Eighty five of the 189 patients with a NFI mutation (45\%) had one of the 38 recurrent mutations and the remaining 104 patients each had a unique, previously undescribed, mutation. About half of patients with NF1 harbour a mutation that would lead to a recurrent alteration in mRNA.

Rapid testing for recurrent mutations might form a first step in routine diagnosis.

A Journal of Medical Genetics 2003;40:e82(http://www.jmedgenet.com/cgi/content/full/40/6/e82) 